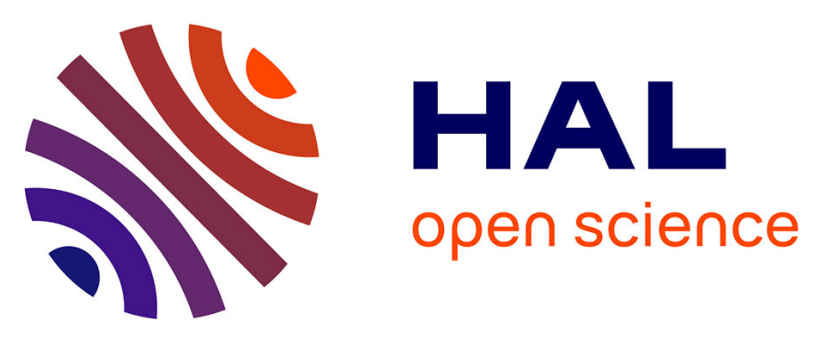

\title{
Influence of breeding sites features on genetic differentiation of Aedes aegypti populations analyzed on a local scale in Phnom Penh Municipality of Cambodia.
} Christophe Paupy, Ngan Chantha, Karine Huber, Nicolas Lecoz, Jean-Marc Reynes, Francois Rodhain, Anna-Bella Failloux

\section{To cite this version:}

Christophe Paupy, Ngan Chantha, Karine Huber, Nicolas Lecoz, Jean-Marc Reynes, et al.. Influence of breeding sites features on genetic differentiation of Aedes aegypti populations analyzed on a local scale in Phnom Penh Municipality of Cambodia.. American Journal of Tropical Medicine and Hygiene, 2004, 71 (1), pp.73-81. 10.4269/ajtmh.2004.71.73 . pasteur-01702881

\section{HAL Id: pasteur-01702881}

\section{https://hal-pasteur.archives-ouvertes.fr/pasteur-01702881}

Submitted on 7 Feb 2018

HAL is a multi-disciplinary open access archive for the deposit and dissemination of scientific research documents, whether they are published or not. The documents may come from teaching and research institutions in France or abroad, or from public or private research centers.
L'archive ouverte pluridisciplinaire HAL, est destinée au dépôt et à la diffusion de documents scientifiques de niveau recherche, publiés ou non, émanant des établissements d'enseignement et de recherche français ou étrangers, des laboratoires publics ou privés.

$$
\text { Copyright }
$$




\title{
INFLUENCE OF BREEDING SITES FEATURES ON GENETIC DIFFERENTIATION OF $A E D E S A E G Y P T I$ POPULATIONS ANALYZED ON A LOCAL SCALE IN PHNOM PENH MUNICIPALITY OF CAMBODIA
}

\author{
CHRISTOPHE PAUPY, NGAN CHANTHA, KARINE HUBER, NICOLAS LECOZ, JEAN-MARC REYNES, \\ FRANCOIS RODHAIN, AND ANNA-BELLA FAILLOUX \\ Unité Insectes et Maladies Infectieuses et Ecole Pasteurienne d'Infectiologie, Institut Pasteur, Paris, France; National Malaria Center, \\ Phnom Penh, Cambodia; Unité de Virologie, Institut Pasteur du Cambodge, Phnom Penh, Cambodia
}

\begin{abstract}
This study analyzed genetic differentiation of 20 Aedes aegypti populations collected along a street in Phnom Penh Municipality of Cambodia. Using allozyme and microsatellite variations, we demonstrated that populations were differentiated and the pattern of differentiation was dependent on the type of breeding sites. Moreover, insecticide treatments with temephos mostly affect the population functioning of discarded containers. Low gene flow detected could limit the natural diffusion of resistant populations that might instead take advantage of human displacements to spread.
\end{abstract}

\section{INTRODUCTION}

Since dengue hemorrhagic fever (DHF) was first described in the mid 1950s, the occurrence of the disease has largely spread. The number of dengue fever (DF) cases has increased worldwide and dengue infection still continues its geographic expansion over Southeast Asia, America, and the Pacific region. ${ }^{1}$ Today, dengue is considered the most important arthropod-born viral disease, and dengue virus causes 50-100 million cases of DF and several hundred thousand cases of DHF each year. ${ }^{2}$ A number of complex factors are related to the emergence and the re-emergence of dengue, particularly population growth, unplanned urbanization, and increased travel by airplane which facilitates the expansion of vectors and dispersion of viruses.

Originally, dengue was restricted to urban centers, but it appears that more and more rural areas in which high numbers of domestic habitats can support large populations of Aedes aegypti have to face dengue outbreaks. ${ }^{3}$ In Cambodia, as in most countries in Southeast Asia, transmission of dengue viruses to humans is ensured mainly by Ae. aegypti (Linné 1762). This highly anthropophilic species is closely associated with a domestic environment in which both blood sources for female mosquitoes to feed on and breeding sites to oviposite are available. ${ }^{4}$ Females usually disperse no more than $1 \mathrm{~km}$ in urban areas. ${ }^{5-8}$ Mosquito dispersal is an epidemiologic concern because it is the mechanism whereby females acquire and disseminate pathogens. In Phnom Penh Municipality of Cambodia, Ae aegypti, which represents at least $40 \%$ of indoor resting mosquitoes, ${ }^{9}$ breeds in various containers because running water systems are not always available. In the city center, only low levels of genetic exchange were detected between populations separated by less than $6 \mathrm{~km} .{ }^{10}$ Household water practices certainly influence larval distribution of the vector. ${ }^{11}$ Thus, this has a significant effect on dengue risk. $^{12}$

Since 1962, Cambodia has regularly been confronted with more severe and recurrent dengue outbreaks. ${ }^{13}$ After the worst recorded outbreak in 1998, which caused 16,216 DHF cases and 475 deaths, ${ }^{14}$ the National Dengue Control Program (known as Mosquitoblitz) set up by the Ministry of Health in 2001 aimed to control dengue vectors using mass larvicide applications (temephos) in drinking water containers (Chantha N, unpublished data). Before dengue vaccines or other measures such as the release of non-competent, ge- netically modified mosquitoes become available, vector control through the use of insecticides remains the only realistic way to limit dengue outbreaks. Control measures could lead to habitat disappearance and thus affect species diversity. Species extinction in urban environments is caused mostly by insecticide uses. Acting as a powerful selection factor, insecticides lead to rapid development of resistance. ${ }^{15}$ Information on genetic variation within and between populations is critical for understanding the evolutionary history of mosquito populations experiencing different environmental constraints. ${ }^{16,17}$

In previous studies, we have investigated genetic differentiation of Ae. aegypti collected in different cities in Cambodia (i.e., the country scale) (Paupy $\mathrm{C}$ and others, unpublished data) and within the city of Phnom Penh (i.e., the city scale). ${ }^{10}$ Our results showed that genetic differentiation estimated in Phnom Penh was low compared with other Asian cities such as Chiang Mai, Thailand ${ }^{18}$ or Ho Chi Minh City, Vietnam. ${ }^{16,17}$ In this study, we have investigated Ae. aegypti populations in a more limited geographic area compatible with the natural flight range of the species. We have assessed these populations using both allozyme and microsatellite variations based on genetic differentiation of populations collected in dwellings along a street in Phnom Penh, and its variation according to water storage devices and insecticide applications.

\section{MATERIALS AND METHODS}

House prospecting and sampling. Twenty samples of $A e$. aegypti larvae and pupae were collected in May 2001 in Phnom Penh. The sampling area was restricted to a single street, Lohat Street, a typical street in the southern suburbs of Phnom Penh. Both individual concrete and wooden houses bordering Lohat Street were inspected after consent was obtained from the inhabitants, and all containers with Ae. aegypti larvae were recorded and sampled. For each sample, we recorded the type of breeding site and the presence or absence of insecticide (usually temephos). Collected samples were reared in insectaries and resulting adults were stored at $-80^{\circ} \mathrm{C}$ until allozyme and microsatellite assays.

Allozyme polymorphism. Each adult mosquito was ground in $25 \mu \mathrm{L}$ of distilled water and centrifuged for five minutes at $15,000 \mathrm{rpm}$ at $4^{\circ} \mathrm{C}$. The pellet was kept for extraction of DNA and the supernatant was loaded onto a $12.8 \%$ starch gel using 
the Tris-maleate-EDTA ( $\mathrm{pH} 7.4$ ) buffer system. The following enzyme systems were studied: glutamate oxaloacetate transaminase (Got1 and Got2, EC 2.6.1.1.), glycerol-3phosphate dehydrogenase (Gpd, EC 1.1.1.8.), hexokinase (Hk1, Hk2, and Hk3, EC 2.7.1.1.), malic enzyme (Me, EC 1.1.40.), malate dehydrogenase (Mdh, EC 1.1.1.37.), phophoglucoisomerase (Pgi, EC 5.3.1.9.), and phosphoglucomutase (Pgm, EC 2.7.5.1.). ${ }^{19}$ For each sample, 18-48 adults were assayed for seven enzyme systems that provided 11 putative genetic loci. A reference control was included in each gel corresponding to females established in an isofemale lineage of Ae. aegypti collected in French Polynesia. ${ }^{19}$ For each locus, alleles have been numbered according to the mobility relative to the most common allele (100) in the reference.

Microsatellite polymorphism. Extraction of DNA and amplification of microsatellites were performed as described by Huber and others. ${ }^{17}$ Five microsatellite loci were analyzed: C2A8, 34/72, T3A7, AED 19, and 38/38. ${ }^{17}$ For each sample studied (Table 1), 28-30 mosquitoes were analyzed.

Statistical analysis. Gene diversity, deviations from HardyWeinberg proportions, genotypic linkage disequilibrium, and genetic differentiation were analyzed using GENEPOP (version 3.3) software. ${ }^{20}$ Gene diversity was calculated using allele identity method (option 5, sub-option 2). Genotypic association between pairs of loci was tested for each sample using Fisher's exact test on rank $\times$ column contingency tables (option 2). Deviations from Hardy-Weinberg proportions in each population and at each locus were investigated (option 1) using an exact approximation proposed by Haldane. ${ }^{21}$ Multilocus estimates of significance for HW equilibrium tests were estimated by Fisher's combined probability test. ${ }^{22}$ Heterozygote deficits or excess were tested using an exact test procedure. ${ }^{23} \mathrm{~F}_{\mathrm{IS}}$ and $\mathrm{F}_{\mathrm{ST}}$ were calculated using the formula of Weir and Cockerham. ${ }^{24}$ Genetic differentiation across populations was estimated by calculating the $P$ value associated with the $F_{\mathrm{ST}}$ estimate (option 3). The overall significance of multiple tests was estimated by Fisher's combined probability test. $^{22}$ Critical significance levels for multiple testing were corrected using sequential Bonferroni procedures. ${ }^{25}$ Genetic isolation by geographic distance was tested by estimating rank correlations between $\mathrm{F}_{\mathrm{ST}} /\left(1-\mathrm{F}_{\mathrm{ST}}\right)$ calculated between pairs of samples and Ln distances. ${ }^{26}$ Analysis of variance (ANOVA) and Kruskal-Wallis tests were performed for mean comparisons using Epi-Info (version 6.04b) software (Centers for Disease Control and Prevention, Atlanta, GA).

\section{RESULTS}

House prospecting. Most (25 of 34) houses bordering the street were inspected, which resulted in the collection of 20 samples of Ae. aegypti from 14 houses (Table 1 and Figure 1). The type of breeding sites was heterogeneous: of 20 samples, 10 were collected from water storage containers (WSC) (e.g., small and large jars) and 10 from discarded containers (DC) (e.g., dish, tray, bucket, kettle, jar, tire, vase) (Table 1). In WSC, larval density (i.e., estimated number of larvae) was higher than in DC. Moreover, nine samples came from houses where temephos had been distributed during the dengue prevention campaign.

Linkage disequilibrium. When linkage disequilibrium between pairs of loci encoding allozymes was assessed, seven non-random associations were detected in 110 possible tests: Hk1-Hk2, Hk1-Hk3, and Hk2-HK3 for samples 9 and 10, and Pgi-Mdh for sample 19. Since loci Hk1, Hk2, and Hk3 seemed to be linked statistically, only $\mathrm{Hk} 1$ was taken into account for further analysis. Analysis of genotypic disequilibrium between pairs of microsatellite loci showed that all loci were statistically independent from each other.

Hardy-Weinberg equilibrium. Among the 11 allozyme loci investigated, two ( $\mathrm{Gpd}$ and $\mathrm{Me}$ ) were monomorphic for the same allele. Loci Hk1, Mdh, Pgi, and Pgm, which segregated in all samples for three or more alleles, were considered. Of 61 tests performed for Hardy-Weinberg equilibrium, only two significant deviations $(P<0.05)$ were detected (Table 2$)$ : the first deviation concerned sample 11 for $\mathrm{Mdh}$, which was due to a heterozygote excess $\left(F_{I S}=-0.506\right)$, while the second

TABLE 1

Features of Aedes aegypti samples collected in Phnom Penh, Cambodia in May 2001

\begin{tabular}{|c|c|c|c|c|c|c|c|}
\hline \multirow{2}{*}{$\begin{array}{c}\text { Sample } \\
\text { no. }\end{array}$} & \multirow{2}{*}{$\begin{array}{c}\text { House } \\
\text { no. }\end{array}$} & \multirow{2}{*}{$\begin{array}{c}\text { Type of } \\
\text { breeding site }\end{array}$} & \multirow{2}{*}{$\begin{array}{c}\text { Volume of } \\
\text { water in } \\
\text { container }(\mathrm{mL})\end{array}$} & \multirow{2}{*}{$\begin{array}{l}\text { Use of temephos } \\
\text { in house } \\
\text { Yes/no* }\end{array}$} & \multirow{2}{*}{$\begin{array}{l}\text { Estimated } \\
\text { number of } \\
\text { larvae }\end{array}$} & \multicolumn{2}{|c|}{ Genetic variation } \\
\hline & & & & & & Allozyme & Microsatellite \\
\hline 1 & 1 & Big jar & 50 & $\mathrm{~N}$ & $>300$ & + & + \\
\hline 2 & 3 & Abandoned dish & 1.5 & $\mathrm{Y}$ & $0-30$ & + & \\
\hline 3 & 3 & Abandoned tray & 1 & $\mathrm{Y}$ & $30-50$ & + & \\
\hline 4 & 5 & Big jar & 300 & $\mathrm{~N}$ & $>300$ & + & \\
\hline 5 & 7 & Big jar & 50 & $\mathrm{~N}$ & $100-150$ & + & \\
\hline 6 & 7 & Big jar & 20 & $\mathrm{~N}$ & $150-300$ & + & \\
\hline 7 & 12 & Bucket & 1 & $\mathrm{~N}$ & $0-30$ & + & + \\
\hline 8 & 12 & Abandoned kettle & 1 & $\mathrm{~N}$ & $0-30$ & + & \\
\hline 9 & 12 & Abandoned jar & 1 & $\mathrm{~N}$ & $30-50$ & + & \\
\hline 10 & 11 & Tire & 0.5 & $\mathrm{Y}$ & $100-150$ & + & \\
\hline 11 & 11 & Small jar & 1.5 & Y & $100-150$ & + & \\
\hline 12 & 13 & Tire & 1 & $\mathrm{~N}$ & $100-150$ & + & + \\
\hline 13 & 16 & Big jar & 30 & $\mathrm{~N}$ & $30-50$ & + & + \\
\hline 14 & 15 & Big jar & 70 & $\mathrm{Y}$ & $100-150$ & + & + \\
\hline 15 & 22 & Big jar & 60 & $\mathrm{~N}$ & $0-30$ & + & \\
\hline 16 & 22 & Small jar & 15 & $\mathrm{~N}$ & $100-150$ & + & + \\
\hline 17 & 19 & Small jar & 10 & $\mathrm{Y}$ & $30-50$ & + & + \\
\hline 18 & 25 & Abandoned jar & 2 & $\mathrm{Y}$ & $150-300$ & + & + \\
\hline 19 & 29 & Flower vase & 0.5 & $\mathrm{Y}$ & $150-300$ & + & + \\
\hline 20 & 36 & Abandoned jar & 5 & $\mathrm{Y}$ & $100-150$ & + & + \\
\hline
\end{tabular}



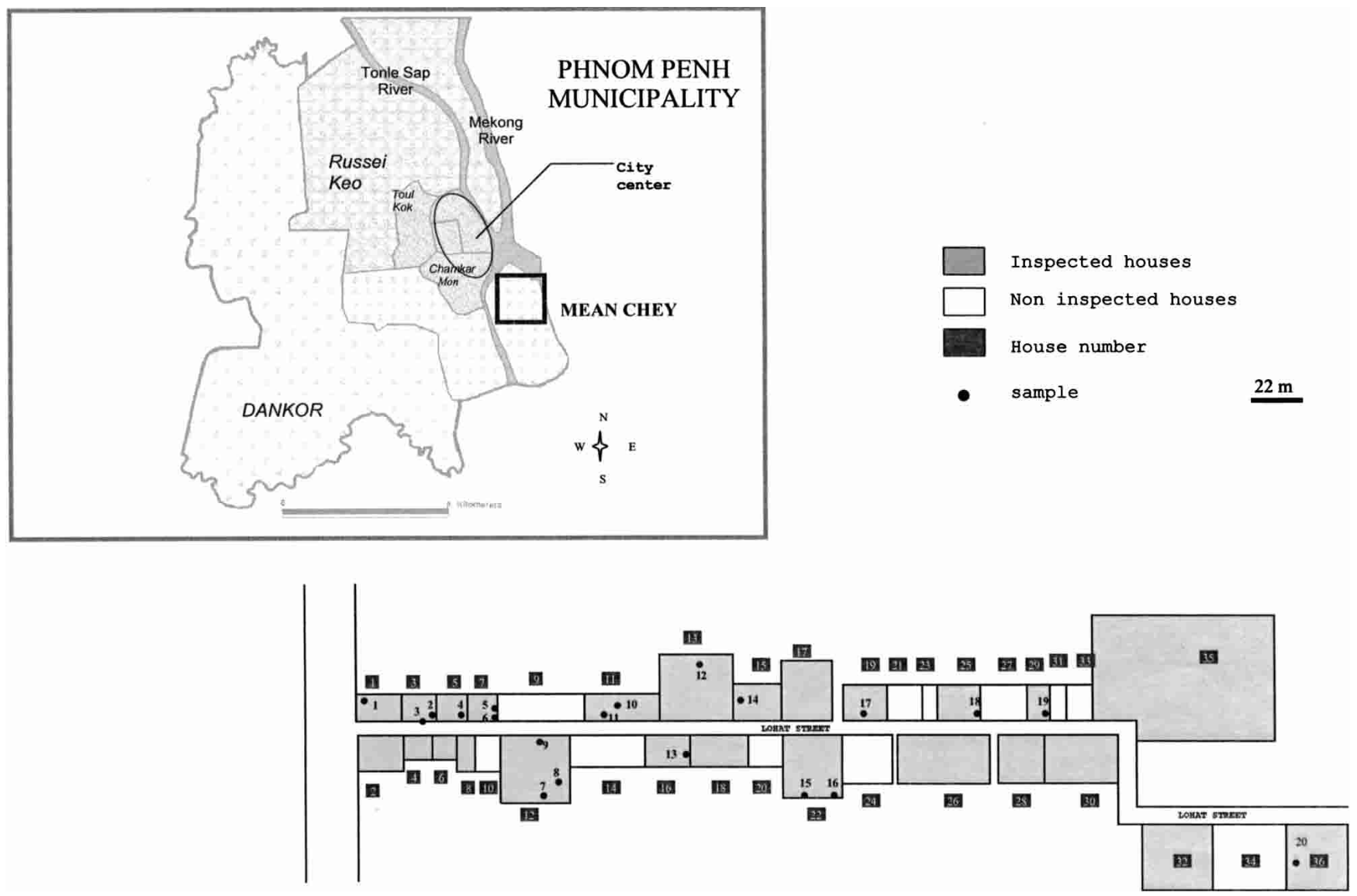

Figure 1. Map showing the geographic location of the Aedes aegypti samples collected in May 2001 in the Mean Chey district of Phnom Penh, Cambodia.

corresponded to sample 3 for Pgm, which was caused by a heterozygote deficit $\left(\mathrm{F}_{\mathrm{IS}}=+0.589\right)$. When all loci were considered together, only sample 11 showed a significant deviation corresponding to a heterozygote excess $\left(P<10^{-4}\right)$.

For microsatellites, of 34 tests conducted, eight deviations from Hardy-Weinberg proportions were detected: samples 1 and 14 for 34/72, samples 12,14 , and 16 for T3A7, and samples 1, 7, and 12 for AED19 (Table 3). All deviations were due to heterozygote deficits. No significant deviation was detected when global tests (i.e., all loci for each sample) were performed.

Gene diversity. Gene diversity (i.e., heterozygosity or average proportion of heterozygotes in a subpopulation) was estimated for all loci in each sample (Table 2). Mean heterozygosity was calculated when grouping samples according to 1) type of breeding sites and 2) presence or absence of temephos treatments. Although the mean \pm SD heterozygosity seemed to be higher for samples collected in WSC $(0.167$ $\pm 0.051)$ than those from AR $(0.148 \pm 0.041)$, no significant difference was detected ( $P=0.37$, by ANOVA). The same tendency was observed when analyzing samples according to temephos treatments. For samples collected in treated sites, the mean \pm SD heterozygosity $(0.162 \pm 0.021)$ was slightly higher than in non-treated sites $(0.154 \pm 0.066)$. However, no significant difference was found between them $(P=0.82$, by ANOVA).

Gene diversity estimated from microsatellite markers was similar $(P=0.53$, by ANOVA $)$ in both types of breeding sites: $0.228 \pm 0.036$ for DC and $0.248 \pm 0.056$ for WSC. When grouping of samples was done according to temephos treatment, no difference ( $P=0.55$, by ANOVA) was found between treated and non-treated groups: $0.235 \pm 0.045$ for treated sites and $0.242 \pm 0.051$ for non-treated sites.

Genetic differentiation. Genetic differentiation assessed using allozymes showed that samples collected in Lohat Street were significantly differentiated $\left(\mathrm{F}_{\mathrm{ST}}=0.046, P<\right.$ 0.0001 ) (Table 4). When estimating more precisely the pattern of differentiation, samples from the two types of breeding sites (i.e., abandoned recipient DC and water storage container WSC) were significantly differentiated $(P<0.0001)$. A higher $\mathrm{F}_{\mathrm{ST}}$ value was estimated for the $\mathrm{DC}$ group $\left(\mathrm{F}_{\mathrm{ST}}=\right.$ 0.071) compared with those calculated for the WSC group $\left(\mathrm{F}_{\mathrm{ST}}=0.029\right)$. When estimating differentiation between pairs of samples, $\theta_{i j}$ ranged from -0.143 to $0.259(0.045 \pm 0.051)$ (Appendix 1): from -0.0060 to 0.2594 for the DC group $(0.070$ $\pm 0.067)$, from -0.0095 to 0.1386 for the WSC group $(0.027 \pm$ $0.030)$, and from -0.143 to 0.1765 for heterologous combinations $(\mathrm{AR} / \mathrm{WSC})(0.045 \pm 0.045)$. The mean $\theta_{i j \text {-wSC }}$ was significantly lower than mean $\theta_{i j \text {-heterologous }}(P=0.023$, by Kruskal-Wallis test). In addition, the latter was significantly lower than the mean $\theta_{i j \text {-DC }}(P=0.036$, by Kruskal-Wallis test). Of 190 combinations, 61 showed significant differentiation $(24.4 \%)$ among which 18 were DC combinations, 10 were WSC combinations, and 33 were AR/WSC combinations. Thus, genetic differentiation of AR/WSC combinations was intermediate between the WSC group and the DC group. 

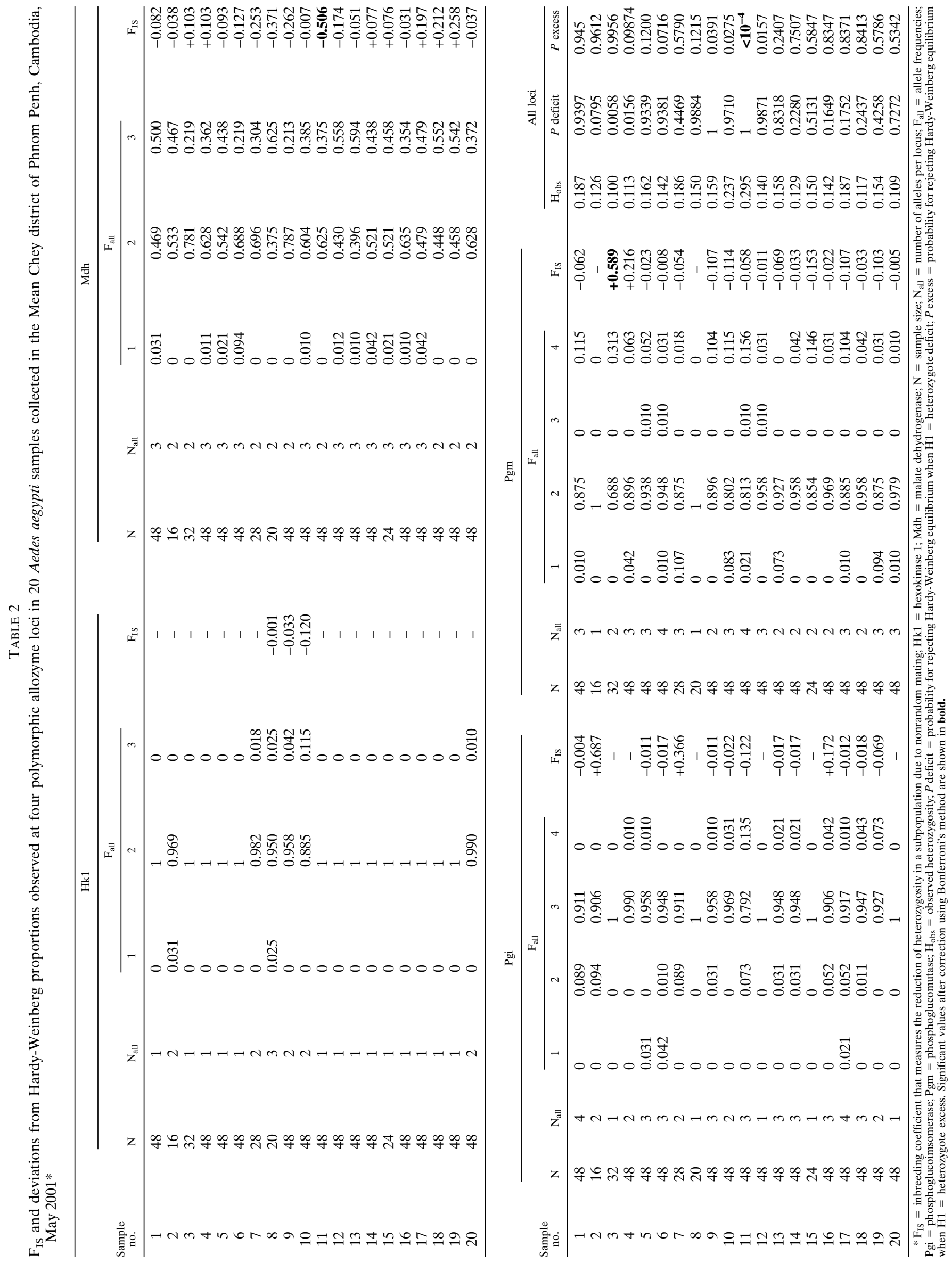

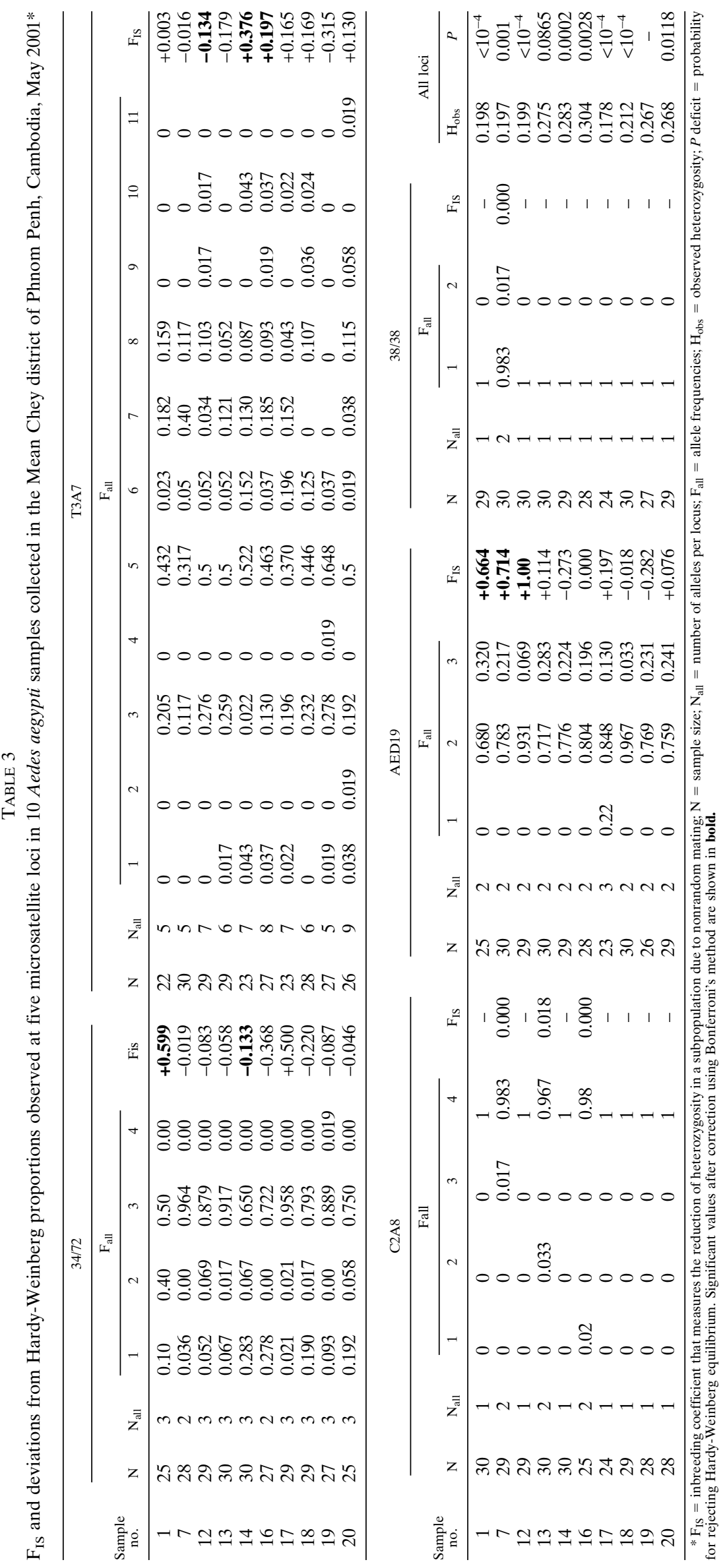
TABLE 4

$\mathrm{F}_{\mathrm{ST}}$ values for estimating Aedes aegypti differentiation based on allozyme and microsatellite polymorphisms according to two types of breeding sites and temephos distribution in Phnom Penh, Cambodia, May 2001

\begin{tabular}{|c|c|c|c|c|c|c|c|c|c|c|c|c|c|}
\hline \multirow[b]{3}{*}{ Comparisons } & \multicolumn{13}{|c|}{$\mathrm{F}_{\text {ST }}$} \\
\hline & \multicolumn{6}{|c|}{ Allozyme } & \multicolumn{7}{|c|}{ Microsatellite } \\
\hline & $\mathrm{N}$ & Pgm & Pgi & Mdh & Hk1 & All loci & $\mathrm{N}$ & $\mathrm{C} 2 \mathrm{~A} 8$ & $34 / 72$ & T3A7 & AED19 & $38 / 38$ & All loci \\
\hline All samples & 20 & $0.050 \dagger$ & $0.034 \dagger$ & $0.046 \dagger$ & $0.061 \dagger$ & $0.046 \dagger$ & 10 & $0.006 \neq$ & $0.116 \dagger$ & $0.033 \dagger$ & $0.032 \dagger$ & -0.001 & $0.053 \dagger$ \\
\hline \multicolumn{14}{|l|}{ Breeding site type } \\
\hline DC & 10 & $0.085 \S$ & $0.027 \dagger$ & $0.075 \dagger$ & $0.051 \S$ & $0.071 \dagger$ & 5 & -0.001 & $0.038 \ddagger$ & $0.062 \dagger$ & $0.053 \ddagger$ & -0.001 & $0.054 \dagger$ \\
\hline WSC & 10 & $0.024 \dagger$ & $0.036 \dagger$ & $0.029 \dagger$ & - & $0.029 \dagger$ & 5 & 0.008 & $0.166 \dagger$ & $0.007 \S$ & 0.004 & - & $0.052 \dagger$ \\
\hline \multicolumn{14}{|c|}{ Temephos treatment } \\
\hline Yes & 9 & $0.074 \dagger$ & $0.047 \dagger$ & $0.029 \dagger$ & $0.086 \dagger$ & $0.045 \dagger$ & 5 & - & $0.060 \S$ & $0.028 \dagger$ & $0.041 \ddagger$ & - & $0.039 \dagger$ \\
\hline No & 11 & $0.021 \dagger$ & $0.014 \S$ & $0.066 \dagger$ & $0.022 \ddagger$ & $0.051 \dagger$ & 5 & 0.003 & $0.188 \dagger$ & $0.029 \ddagger$ & $0.030 \S$ & - & $0.067 \dagger$ \\
\hline
\end{tabular}

${ }^{*} \mathrm{~F}_{\mathrm{IS}}=$ inbreeding coefficient that measures the reduction of heterozygosity in a subpopulation due to nonrandom mating; $\mathrm{N}=$ number of samples; Pgm $=$ phosphoglucomutase; Pgi $=$ phosphoglucoimsomerase; $\mathrm{Mdh}=$ malate dehydrogenase; Hk1 = hexokinase 1; DC = discarded container; WSC = water storage container. Significant $P$ values for homogeneity by Fisher's exact test are shown in bold.

$\dagger P<0.0001$

$\doteqdot P<0.05$.

$\S P<0.001$.

When samples were pooled according to temephos treatment (Table 4), significant differentiation was detected in both groups $(P<0.0001)$. The $\mathrm{F}_{\mathrm{ST}}$ value estimated from samples collected in treated houses $\left(\mathrm{F}_{\mathrm{ST}}=0.045\right)$ was similar to the $F_{\mathrm{ST}}$ value calculated from samples in non-treated houses $\left(\mathrm{F}_{\mathrm{ST}}=0.051\right)$. When genetic differentiation was estimated for pairs of samples, $\theta_{i j}$ values ranged from -0.014 to $0.195(0.046 \pm 0.052)$ for the group corresponding to treated samples, from -0.009 to $0.208(0.049 \pm 0.051)$ for the group of non-treated samples, and from -0.008 to 0.259 $(0.042 \pm 0.049)$ for heterologous comparisons (treated/nontreated) (Appendix 2). Of the 61 significant combinations, 30 were treated/non-treated combinations, 19 were treated combinations, and 12 were non-treated combinations. The mean $\theta_{i j \text {-treated }}, \theta_{i j \text {-non-treated }}$ and $\theta_{i j \text {-heterologous were similar }}$ $(P=0.813$, by ANOVA $)$.

When genetic divergence was estimated according to geographic distance, the relation $F_{\mathrm{ST}} /\left(1-F_{\mathrm{ST}}\right)=\mathrm{a}+\mathrm{b}(\mathrm{Ln}$ distance) was not significant when one considered 1) all samples collected in Lohat Street $(P=0.662), 2)$ only samples from WSC $(P=0.797)$, and 3$)$ only samples from DC $(P=0.629)$.

When all microsatellite loci were considered, genetic differentiation estimated for the 10 samples was significant $\left(\mathrm{F}_{\mathrm{ST}}\right.$ $=0.053, P<0.0001$ ) (Table 4). When differentiation was assessed considering pairs of samples, $\theta_{i j}$ ranged from -0.0034 to $0.1241(0.051 \pm 0.036)$. The level of genetic differentiation within each group (DC and WSC) was significant $(P<0.0001)$ and similar (i.e., $\mathrm{F}_{\mathrm{ST}}=0.054$ for the $\mathrm{DC}$ group and $\mathrm{F}_{\mathrm{ST}}=$ 0.052 for the WSC group). When pairs of samples were considered, $\theta_{i j \text {-DC }}$ ranged from 0.003 to $0.110(0.052 \pm 0.039)$, $\theta_{i j \text {-wsC }}$ from -0.005 to $0.122(0.052 \pm 0.036)$, and $\theta_{i j \text {-heterologous }}$ from -0.003 to $0.124(0.050 \pm 0.037)$. Of 45 possible combinations, 26 were significant $(P<0.05)$ with 15 referring to heterologous combinations. When comparing mean distributions, no significant difference $(P>0.05$, by ANOVA) was detected. Using microsatellites, no particular pattern of differentiation was detected.

Even if differentiation was significant $(P<0.0001)$, samples originated from treated houses were less differentiated $\left(\mathrm{F}_{\mathrm{ST}}\right.$ $=0.0392)$ than those from non-treated houses $\left(\mathrm{F}_{\mathrm{ST}}=0.0667\right)$ (Table 4). When examining pairs of samples (Appendix 2), $\theta_{i j}$ ranged from -0.005 to 0.124 . When mean distributions of $\theta_{i j}$ values in each group were compared, no significant difference $(P=0.250$, by ANOVA) was detected.

When estimating genetic divergence according to geographic distance, the relationship $\mathrm{F}_{\mathrm{ST}} /\left(1-\mathrm{F}_{\mathrm{ST}}\right)=\mathrm{a}+\mathrm{b}(\mathrm{Ln}$ distance) was not significant when 1$)$ all samples $(P=0.258)$, 2) samples from WSC $(P=0.178)$, and 3$)$ samples from DC $(P=0.312)$ were considered.

\section{DISCUSSION}

We demonstrated that (1) Ae. aegypti populations were highly differentiated in the Lohat street, (2) the pattern of genetic differentiation depends on the type of breeding sites (pairs of DC samples were more differentiated than an DC sample was with an WSC sample or between two WSC samples), and (3) insecticide treatment mostly affects the population functioning of DC.

Curiously, the level of genetic differentiation $\left(\mathrm{F}_{\mathrm{ST}}=0.046\right)$ estimated for all 20 Ae. aegypti samples collected in Lohat Street using allozyme is more important than that observed for populations collected in the whole municipality of Phnom Penh $\left(\mathrm{F}_{\mathrm{ST}}=0.027\right)$ (Paupy $\mathrm{C}$ and others, unpublished data). In this latter study, only WSC were sampled in the city center. When only WSC samples were taken into account in the present study, the level of genetic differentiation decreases (Paupy $\mathrm{C}$ and others, unpublished data). Low levels of genetic differentiation have also been recorded for Ae. aegypti in San Juan, Puerto, suggesting that females tend to oviposite only a few eggs in individual sites and to disperse over long distances. ${ }^{27}$ Thus, even if the collected samples were a maximum of 400 meters apart, a distance compatible with Ae. aegypti natural flight range in cities, ${ }^{28}$ mosquito differentiation remains significant along Lohat Street. More polymorphic markers such as microsatellites can detect higher level of genetic differentiation (i.e., higher $\mathrm{F}_{\mathrm{ST}}$ values; see Table 4 for more details) and could be proposed to evaluate genetic structure at a street scale.

The type of breeding sites tends to influence the level of genetic differentiation. Allozyme analysis revealed that $A e$. aegypti populations from abandoned containers (i.e., peridomestic breeding sites) were more differentiated than are those from WSC (i.e., domestic breeding site). Water jars are rarely 
emptied, ensuring permanent larval production throughout the year. ${ }^{10,15}$ Conversely, DC harbor larvae only in the rainy season. Populations could stem from dry eggs or from eggs laid de novo by females from neighboring breeding sites and, particularly, from domestic jars. The ecologic constraints (e.g., small amounts of water and food) that mosquitoes from DC have to face limit larval production. ${ }^{29}$ Recurrent extinction events and founder effects enhance the inter-DC differentiation. Migration is more limited between populations from DC than between those from permanent water-filled containers. Migrants can be detected between permanent jars and temporary breeding sites as demonstrated by Huber and others $^{12}$ in Ho Chi Minh City, Vietnam.

Aesdes aegypti populations in Phnom Penh have been exposed to temephos every 6-7 weeks since the setting up of the campaign Mosquitoblitz in 2001. Most water storage collections were treated with the larvicide. The efficiency of these treatments was assessed by the calculation of the Breteau index (number of jars with larvae for 100 houses); this index decreased from more than 50 to less than 5 one week after insecticide application. Unfortunately, the index recovered its pretreatment level seven weeks after the end of the treatment (Chantha N, unpublished data). Populations have therefore experienced intense selection by insecticides that probably resulted in periodic population bottlenecks. Thus, genetic polymorphism is expected to decrease rapidly during insecticide use. ${ }^{30}$ Mean heterozygosities of our populations are low, confirming weak gene flow between them. During the insecticidal campaign, collections for household use were mainly treated, thus becoming unsuitable for females in which to oviposite. Thus, females were compelled to migrate in the search of untreated breeding sites (non-treated jars or DC) producing a mixture of two or more subpopulations. Thus, a reduction in the number of heterozygotes can be detected (the Walhund effect).

Our study confirms the different population functioning between peridomestic DC (temporal, small effective size) and domestic water storage (permanent, large effective size). Aedes aegypti females tend to oviposite in many sites, preferentially in WSC; thus, a single oviposition container may contain a mixture of several families that decreases genetic differentiation between neighboring sites. Domestic containers were more subjected to insecticide treatments that induce recurrent extinctions and emergence of insecticide-resistant populations. Thus, alleles conferring insecticide resistance could be rapidly fixed and invade untreated peridomestic sites. Moreover, resistant populations could spread at a larger scale assisted by human displacements. ${ }^{31,32}$ Thus, insecticide treatments of WSC should be associated with destruction of peridomestic breeding sites containing a part of Ae. aegypti populations.

Received September 18, 2003. Accepted for publication October 30, 2003.

Acknowledgments: We are grateful to the "Fondation de France, Jeunesse Internationale" for providing a six-month fellowship to Christophe Paupy during his training at the Pasteur Institute in Cambodia. We thank Nadia Ayad, Laurence Mousson, Regine Villeret, and Marie Vazeille for technical assistance. We also thank the staff of the Unite de Virologie, Institut Pasteur du Cambodge), the National Malaria Center, and the municipality of Phnom Penh for their invaluable help in mosquito collections. We are indebted to Professor JeanLuc Durosoir (Pasteur Institute, Paris, France), Professor Yves Buis- son (Pasteur Institute, Phnom Penh, Cambodia), and Eliane Chungue (Pasteur Institute, Noumea, New Caledonia) for their constant support.

Financial support: This research was supported by the program ACIP "Action Concertée des Instituts Pasteur" (no. 41204).

Authors' addresses: Christophe Paupy, Laboratoire de Microbiologie et Environnement, Institut Pasteur de La Nouvelle Calédonie, BP 61 , 98845 Noumea, New Caledonia. Ngan Chantha, National Malaria Center, 372 Boulevard Monivong, Phnom Penh, Cambodia. Karine Huber, Nicolas Lecoz, and Anna-Bella Failloux, Unité Insectes et Maladies Infectieuses, Institut Pasteur, 25-28 Rue du Dr. Roux, 75724 Paris Cedex 15, France, Telephone: 33-1-40-61-36-17, Fax: 33-1-4061-30-89, E-mail: afaillou@pasteur.fr. Jean-Marc Reynes, Unité de Virologie, Institut Pasteur du Cambodge, 5 Boulevard Monivong, Phnom Penh, Cambodia. Francois Rodhain, Ecole Pasteurienne d'Infectiologie, Institut Pasteur, 25-28 Rue du Dr. Roux, 75724 Paris Cedex 15, France.

\section{REFERENCES}

1. Gubler DJ, 2002. Epidemic dengue/dengue hemorrhagic fever as a public health, social and economic problem in the 21 st century. Trends Microbiol 10: 100-103.

2. Lam SK, 1998. Emerging infectious diseases-Southeast Asia. Emerg Infect Diseases 4: 145-147.

3. Pant CP, Jatanasen S, Yasuno M, 1973. Prevalence of Aedes aegypti and Aedes albopictus and observations on the ecology of dengue haemorrhagic fever in several areas of Thailand. Southeast Asian J Trop Med Public Health 4: 113-121.

4. Strickman D, Kittayapong P, 1993. Laboratory demonstration of oviposition by Aedes aegypti (Diptera: Culicidae) in covered water jars. J Med Entomol 30: 947-949.

5. Trpis M, Hausermann W, 1986. Dispersal and other population parameters of Aedes aegypti in an African village and their possible significance in epidemiology of vector-borne diseases. Am J Trop Med Hyg 35: 1263-1279.

6. Reiter P, Amador MA, Anderson RA, Clark GG, 1995. Dispersal of Aedes aegypti in an urban area after blood feeding as demonstrated by rubidium-marked eggs. Am J Trop Med Hyg 52: 177-179.

7. Ordonez-Gonzales JG, Mercado-Hernandez R, Flores-Suarez AE, Fernandez-Salas I, 2001. The use of sticky ovitraps to estimate dispersal of Aedes aegypti in northeastern Mexico. J Am Mosq Control Assoc 17: 93-97.

8. Tsuda Y, Takagi M, Wang S, Wang Z, Tang L, 2001. Movement of Aedes aegypti (Diptera: Culicidae) released in a small isolated village on Hainan Island, China. J Med Entomol 38: 9398.

9. Kohn M, 1990. A survey on indoor resting mosquito species in Phnom Penh, Kampuchea. Folia Parasitol 37: 165-174.

10. Paupy C, Chantha N, Reynes JM, Failloux AB, 2003. Variation over space and time of Aedes aegypti in Phnom Penh (Cambodia): genetic structure and oral susceptibility to a dengue virus. Genet Res (in press).

11. Moore CG, Cline BL, Ruiz-Tiben E, Lee D, Romney-Joseph H, Rivera-Correa E, 1978. Aedes aegypti in Puerto-Rico: environmental determinants of larval abundance and relation to dengue virus transmission. Am J Trop Med Hyg 27: 1225-1231.

12. Huber K, Luu Le L, Tran Huu H, Tran Khan T, Rodhain F, Failloux AB, 2002. Temporal genetic variation in Aedes aegypti populations in Ho Chi Minh City (Vietnam). Heredity 89: 7-14.

13. Rathavuth H, Vaughn DW, Minn K, Nimmannitya S, Nisalak A, Raengsakulrach B, Rorabaugh ML, Yuvatha K, Sophal O, 1997. Hemorrhagic fever in Cambodia is caused by dengue viruses: evidence of transmission of all four serotypes. Southeast Asian J Trop Med Public Health 28: 120-125.

14. Chantha N, Guyant P, Hoyer S, 1999. Control of DHF outbreak in Cambodia, 1998. Dengue Bull 22 (http://w3.whosea.org/ DengueBulletin22/ch12.htm).

15. Rawlins SC, Wan JH, 1995. Resistance in some Caribbean populations of Aedes aegypti to several insecticides. J Am Mosq Control Assoc 11: 59-65. 
16. Tran Khanh T, Vazeille-Falcoz M, Mousson L, Tran Huu H, Rodhain F, Nguyen Thi H, Failloux AB, 1999. Aedes aegypti in Ho Chi Minh City (Vietnam): susceptibility to dengue 2 virus and genetic differentiation. Trans $R$ Soc Trop Med Hyg 93: 581-586.

17. Huber K, Luu Le L, Tran Huu H, Ravel S, Rodhain F, Failloux $\mathrm{AB}, 2002$. Genetic differentiation of the dengue vector Aedes aegypti (Ho Chi Minh City, Viet Nam) using microsatellite markers. Mol Ecol 11: 1629-1635.

18. Mousson L, Vazeille M, Chawprom S, Prajakwong S, Rodhain F, Failloux AB, 2002. Genetic structure of Aedes aegypti populations in Chiang Mai (Thailand) and relation with dengue transmission. Trop Med Int Health 7: 865-872.

19. Paupy C, Vazeille-Falcoz M, Mousson L, Rodhain F, Failloux AB, 2000. Aedes aegypti in Tahiti and Moorea (French Polynesia): isoenzyme differentiation in the mosquito population according to human population density. Am J Trop Med Hyg 62: 217-224.

20. Raymond M, Rousset F, 1995. GENEPOP (version 1.2): population genetics software for exact tests and ecumenicism. $J$ Hered 86: 248-249.

21. Haldane JBS, 1954. An exact test for randomness of mating. J Genet 52: 631-635.

22. Fisher RA, 1970. Statistical Methods for Research Workers. 14th edition. Edinburgh: Olivier and Boyd.

23. Rousset F, Raymond M, 1995. Testing heterozygote excess and deficiency. Genetics 140: 1413-1419.

24. Weir BS, Cockerham CC, 1984. Estimating F-statistics for the analysis of population structure. Evolution 38: 1358-1370.
25. Holm S, 1979. A simple sequentially rejective multiple test procedure. Scand J Stat 6: 65-70.

26. Slatkin M, 1993. Isolation by distance in equilibrium and nonequilibrium populations. Evolution 47: 264-279.

27. Apostol BL, Black WC, Reiter P, Miller BR, 1996. Population genetics with RAPD-PCR markers: the breeding structure of Aedes aegypti in Puerto Rico. Heredity 76: 325-334.

28. Honorio N, Da Costa Silva W, José Leite P, Monteiro Gonçalves J, Lounibos LP, Lourenço-de-Oliveira R, 2003. Dispersal of Aedes aegypti and Aedes albopictus (Diptera: Culicidae) in an urban endemic dengue area in the state of Rio de Janeiro, Brazil. Mem Inst Oswaldo Cruz 98: 191-198.

29. Strickman D, Kittayapong P, 2003. Dengue and its vector in Thailand: calculated transmission risk from total pupal counts of Aedes aegypti and association of wing-length measurements with aspects of the larval habitats. Am J Trop Med Hyg 68: 209-217.

30. Lerdthusnee K, Chareonviriyaphap T, 1999. Comparison of isozyme patterns of Aedes aegypti populations collected from pre- and post-Bacillus thuringiensis israelensis treatment sites in Thailand. J Am Mosq Control Assoc 15: 48-52.

31. Huber K, Luu Le L, Chantha N, Failloux AB, 2003. Human displacements shape Aedes aegypti gene flow in Southeast Asia. Acta Trop: (in press).

32. Raymond M, Callaghan A, Fort P, Pasteur N, 1991. Worldwide migration of amplified insecticide resistance genes in mosquitoes. Nature 350: $151-153$ 


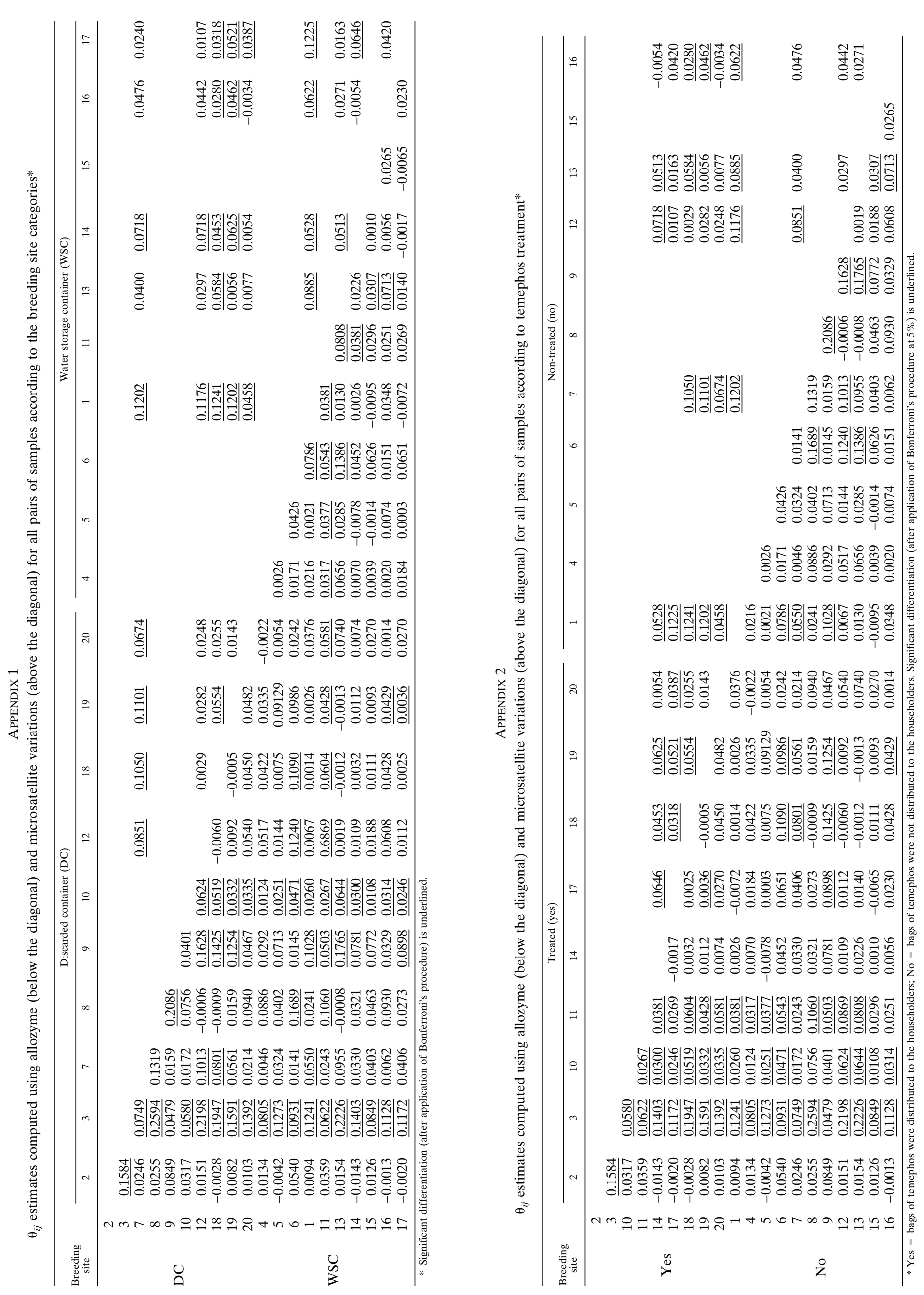

